\title{
Electron Microscopy of Acid Phosphatase Activities in Subcutaneous Connective Tissue Cells of Rabbit
}

\author{
By \\ Katsuhiro Nakamura and Itaru Watanabe \\ From the Department of Pathology, Tohoku University School of \\ Medicine, Sendai; Director: Prof. K. Akazaki \\ (Received for publication, April 2, 1965)
}

\begin{abstract}
Acid phosphatase activities of subcutaneous connective tissue cells of the rabbit in untreated and activated states were studied electron-microscopically. The acid phosphatase activities, represented by lead precipitation, appeared in the three different sites of the cytoplasma: the phagocytotic vacuoles in the activated histiocytes, the Golgi area in these cells as diffuse particulate matter and the ovoid granules sized 0.5 to $1.0 \mu$ in the fibrocyte of the untreated animal. The nature of the enzyme bearing third granules was discussed thereby from the viewpoint of the relation between the mitochondria and the lysosomes.
\end{abstract}

Current interest in the combination of cytochemical staining techniques for enzyme localization with electron microscopy has made an acceptable compromise with us to use aldehydes as fixatives. ${ }^{6,12}$

While, in our laboratory the cytological investigations of the $\mathrm{RE}_{\text {-cells have }}$ been carried out. For instance, Hosoda ${ }^{7}$ in the histochemical researches, observed that the RE-cells changed their several enzyme activities under various functional conditions. Among these enzymes, the behavior of the acid phosphatase activity has been considered to reflect well the function of RE-cells. ${ }^{2,7}$

This preliminary report is aimed to clarify the detailed localization of the acid phosphatase activity using electron microscope.

The material chosen for the experiment was the subcutaneous connective tissue of the rabbit under untreated and activated states.

\section{MATERIALS AND METHODS}

Subcutaneous connective tissues were removed from the back of female rabbits weighing $1.5-2.0 \mathrm{~kg}$. For the activation of the cell system, 0.2 ce of typhoid vaccine was injected at the site, where the materials were removed 4 days thereafter.

Prefixation was made after Holt and Hicks ${ }^{6}$ with some modifications. That is,

中村克宏, 渡辺 至 
the materials were fixed en bloc for $15 \mathrm{~min}$ at $0-4^{\circ} \mathrm{C}$ in $1,2,4$ or $10 \%$ formalin respectively, which was adjusted to $\mathrm{pH} 7.2$ with $\mathrm{M} / 20$ veronal buffer and added with $5 \%$ sucrose.

Immediately after the prefixation, the materials were incubated into the following staining medium, for 1 to 2 hours at $37^{\circ} \mathrm{C}$.

$\mathrm{M} / 20$ acetate buffer $\mathrm{pH} 4.7 \quad \ldots .500 \mathrm{ml}$

$3 \% \beta$-glycerophosphate $\mathrm{Na} \ldots . .50 \mathrm{ml}$

$\mathrm{Pb}\left(\mathrm{NO}_{3}\right)_{2} \quad \ldots \ldots \ldots \ldots \ldots \ldots .6 .6 . \ldots .6$

Formalin to the final concentration of $1 \%$

Sucrose " $" 5 \%$

After the incubation the materials were rinsed in veronal buffer with $5 \%$ sucrose for $15 \mathrm{~min}$ in 3 changes, and were postfixed in veronal buffered $1 \% \mathrm{O}_{5} \mathrm{O}_{4}$ solution for 2 hours at $4^{\circ} \mathrm{C}$. After the postfixation the materials were rinsed in distilled water briefly, dehydrated in graded ethanol and then embedded in "Epon".

In the staining media without substrate or with $0.01 \mathrm{M} \mathrm{NaF}$, the same enzyme reaction was detected as the control.

On the same specimens the development was made with $\left(\mathrm{NH}_{4}\right) \mathrm{Sx}$ after incubation. Then, the materials were stretched on the slide glass and light microscopical observations were made.

\section{OBSERVATION}

\section{Concentration of formalin solution}

We used formalin at different concentration as fixatives, because the original Holt's $^{6}$ method did not always preserve sufficiently the fine structure of subcutaneous connective tissue cells. The authors had to decide the most adequate concentration of the fixative for the tissue. Two and $1 \%$ formalin solution seemed to yield the best result, while $10 \%$ solution made the specimens somewhat shrinked and the intracytoplasmic components were also condensed in general. The following observations were thus achieved in the use of $2 \%$ formalin solution as prefixatives.

\section{Typhoid vaccine treated case}

Four days after the local administration of typhoid vaccine the subcutaneous connective tissue cells changed their forms remarkably. Cell organelles also differentiated to show the own morphological characteristics. As for the mitochondria, for instance, they changed the shape slender tubular, the cristae mitochondriales being distinct to observe. Moreover, as the direct reflection of increased phagocytosis, the ingested material was often observed in the cytoplasma of histiocytes. While, in the fibroblast the Golgi apparatus was well developed along 
with the abundant granular endoplasmic reticulum. Under such a circumstance lead impregnation occurred in phagocytotic vacuoles of histiocytes as noted before in light microscopy. The phagocytotic vacuole was 1 to $3 \mu$ in diameter and delineated by single unit membrane. In many cases the inside wall of the vacuole was impregnated with lead deposits as homogeneous strands. Sometimes, the vacuole contained lead deposits in the clump (Fig. 1). In some free round histiocytes (Fig. 2) there appeared diffuse particulated lead impregnation at the Golgi area. However, it was not distinctly correspondent to the Golgi granules which were 0.1 to $0.5 \mu$ in diameter and revealed high election density (Fig. 3). At this preliminary experiment we also could not decide whether the Golgi lamellae were positive in acid phosphatase activity or not. Neither the mitochondria which were provided with distinct cristae mitochondriales nor granular endoplasmic reticulum showed any lead impregnation. Nuclear staining appeared when the specimens were kept prolonged in formalin-prefixative and/or incubated in the substrate medium too long.

\section{Untreated case}

In the untreated cases, the subcutaneous connective tissue cells showed very weak enzyme activities under light microscopy. As Watanuki ${ }^{13}$ in this laboratory stated before in the subcutaneous connective tissue of the untreated rabbit, about 70 to $80 \%$ of the connective tissue cells were fibrocytes, and 10 to $20 \%$ were histiocytes. The characteristic cell organelles of the former were a number of agranular endoplasmic reticulum and a few slender granular ones. Besides, they contained in the cytoplasma some granules which were 0.5 to $1.0 \mu$ in size and sometimes provided with a few cristae mitochondriales even shorter in length (Fig. 4). The electron density of the ground substance of the granules was medium and homogeneous. There observed no other structure like mitochondria in these cells. The Golgi complex was also not prominent. So, the fibrocyte was rather different in cell organelles from the fibroblast which was characteristic in a large number of granular endoplasmic reticulum and conspicuous Golgi apparatus (Fig. 5). When they were incubated in the medium for acid phosphatase activity, the lead precipitation appeared in some of the ovoid granules sized 0.5 to $1.0 \mu$. The reaction product accumulated near the membrane wall of granules as dots or filled compactly the inside (Fig. 6). The cristae mitochondriales were hardly discernible in these enzyme active granules.

No lead impregnation was seen throughout the experiment when the materials were incubated in the staining media without substrate or with an inhibitor of acid phosphatase.

\section{COMMENT}

One of the problems which bothered the authors was the prefixation of the 
material which had to preserve enzyme activity as well as to sustain ultrastructural integrity in the process of incubation in the staining media. After some triales, we prolonged the prefixation time to 30 minutes with $2 \%$ formalin, and added the $2 \%$ formalin into the staining media, so that the fixation may continue even in the staining procedure at $37^{\circ} \mathrm{C}$. Thus, the nuclear impregnation with lead precipitates could be also avoided. Sucrose was added at a concentration of $5 \%$ without any trouble into prefixatives, incubating media and rinsing solutions respectively. In spite of careful treatments, maintenance of ultrastructure was still inferior to the preparation by immediate fixation of $\mathrm{O}_{5} \mathrm{O}_{4}$. Other aldehydes as fixatives, recently available, ${ }^{12}$ should be tried for the enzyme cytochemical assay.

Since original description of de Duve et al. ${ }^{4}$ about lysosome which was provided with a series of hydrolytic enzymes as a marker, particular attention has been paid to this granular organella. The granules which contained phagocytized material soon became unvailed to be positive in acid phosphatase activity. ${ }^{2}$ The phagocytotic granules or vacuoles are however secondarily formed in the cytoplasma through cell membrane invagination which is induced by contact of foreign particle to the cell. Therefore, if the phagocytotic granules would turn themlseves positive to acid phosphatase activity, it should be demanded that there would preexist the acid phosphatase in the cytoplasma, so to speak, as primary lysosome. This problem was clearly settled, when Sabatini et al. ${ }^{12}$ demonstrated in the kidney tubule cells that the Golgi lamellae and granules were also positive in acid phosphatase activity.

In our observation the phagocytotic vacuoles always showed lead impregnation. Regret to say, however, we could not demonstrate lead impregnation on the Golgi apparatus, especially on the Golgi granules. This did not mean, of course, the opposition of Sabatini's finding but our unsuitable choice of the materials. Because in the histiocytes which appeared in the foci 3 to 5 days after local injection of typhoid vaccine the Golgi granules seemed to lose their contents through rupture of the granules themselves (Fig. 3). By this process, the histiocytes would disperse the enzymes throughout the cytoplasma as a form of fine particles. Fig. 2 seemed to show such a circumstance. The enzyme thus changed into particulate form would secondarily concentrate into phagocytotic granules or vacuoles. While, the Golgi granules seemed to invade directly into the phagocytotic granules or vacuoles, for instance, when the subcutaneous connective tissue cells were stained vitally with trypan blue ${ }^{9}$ or when the Kupffer's stellate cells were loaded with intravenously injected dextran iron. ${ }^{3}$ Endeavored effort to demonstrate acid phosphatase precisely on the Golgi granules of histiocytes should be continued.

The second problem discussed here concerning the lysosome was the interrelationship between this organella and the mitochondrion. The microbody which was supposed by Rouiller and Bernhard11 to transform into mitochondria under regenerating or pathological conditions of liver, has been considered to be lysosome 
since Novikoff and Essner ${ }^{10}$ demonstrated the acid phosphatase activity on this kind of organella. And more recently de Duve ${ }^{5}$ proposed to signify the third granules which were specifically rich in uricase etc, as the microbody.

However, we found the acid phosphatase activity on such granules which had a close resemblance to the mitochondrion in the untreated subcutaneous connective tissue cells (Fig. 6). The granular organella in the connective tissue cells got differentiate to show its morphological integrity when they were in the activated state. So, we suppose that we could not distinguish the mitochondria from the lysosomes but there would exist the rather primitive granules of amphoteric nature. Hudson and Hartmann ${ }^{8}$ on the other hand observed the neurons under axonal section and stated that the dense body which assumed to be the lysosomes transformed into the mitochondria. Ashford and Porter ${ }^{1}$ suggested in liver cells that microbody was a source of acid phosphatase and delivered it to the lysosome. Moreover, Watanuki ${ }^{13}$ in our laboratory had precisely studied the subcutaneous connective tissue cells of the rabbit with the supravital staining, finding in the fibrocyte the granules which stained in both Janus green and neutral red bichromatically other than the usual ones which were positive to Janus green and neutral red respectively. The Janus green positive granules are without doubt the mitochondria. And the neutral red positive granules have been supposed to correspond to lysosomes. ${ }^{7}$ These findings seem to support the veiw. However, further experiments have to be made also in these respects.

\section{References}

1) Ashford, P. Jr. \& Porter, K.R. J. biophys. biochem. Cytol., 1962, 12, 198.

2) Barka, T. J. Histochem. Cytochem., 1962, 10, 231.

3) Daems, W.T. Electron Microscopy, Vol. 2, VV-12, fifth internat. congress for E.M., Philadelphia, 1962.

4) de Duve, C., Pressman, B.C., Gianetto, R., Wattiaux, R. \& Applemans, F. Biochem. $J ., 1955,60,604$.

5) de Duve, C. Nature, 1960, 187, 836.

6) Holt, S.J. \& Marian Hicks, R. J. biophys. biochem. Cytol., 1961, 11, 47.

7) Hosoda, S. Trans. Soc. Path. jap. (Jap.), 1961, 50, 23.

8) Hudson, G. \& Hartmann, J.F. Exp. Cell Res., 1961, 24, 440.

9) Imai, Y. Acta haemat. jap. (Jap.), 1962, 25, 114.

10) Novikoff, A.B. \& Essner, E. J. biophys. biochem. Cytol., 1962, 15, 140.

11) Rouiller, C. \& Bernhard, W. ibid., 1956, Suppl. 2, 355.

12) Sabatini, D.D., Bensch, K. \& Barmott, R. J. Cell Biol., 1963, 17, 19.

13) Watanuki T. Trans. Soc. Path. jap. (Jap.), 1962, 51, 114. 
Figures 1, 2 and 6 were obtained from the material incubated in the medium for acid phosphatase activity, while the others were those from the routine $\mathrm{O}_{\mathrm{s}} \mathrm{O}_{4}$ fixation without incubation.

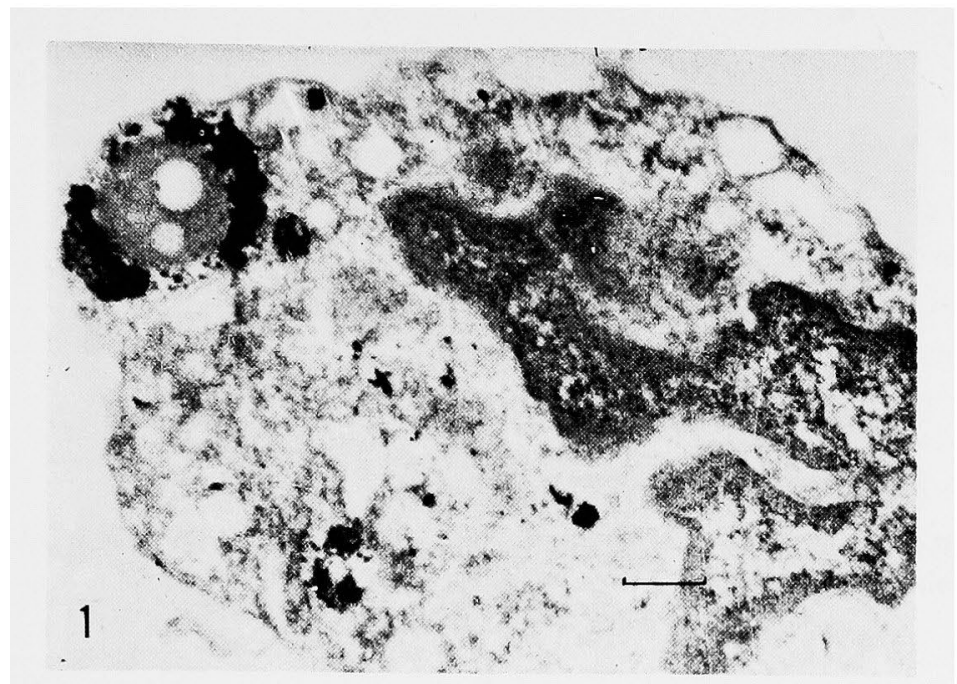

Fig. 1. Phagocytized histiocyte, 4 days after local injection of typhoid vaccine. Lead impregnation is seen at the margin of phagocytotic granule.

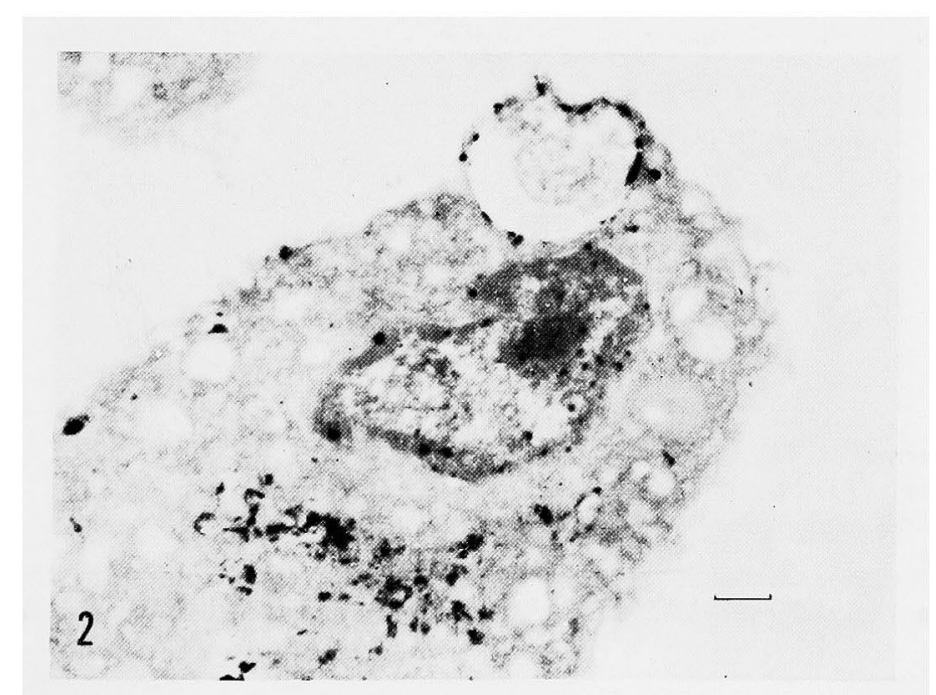

Fig. 2. Free round histiocyte, 4 days after local injection of typhoid vaccine. Diffuse particulate lead impregnation is seen in the Golgi area. 


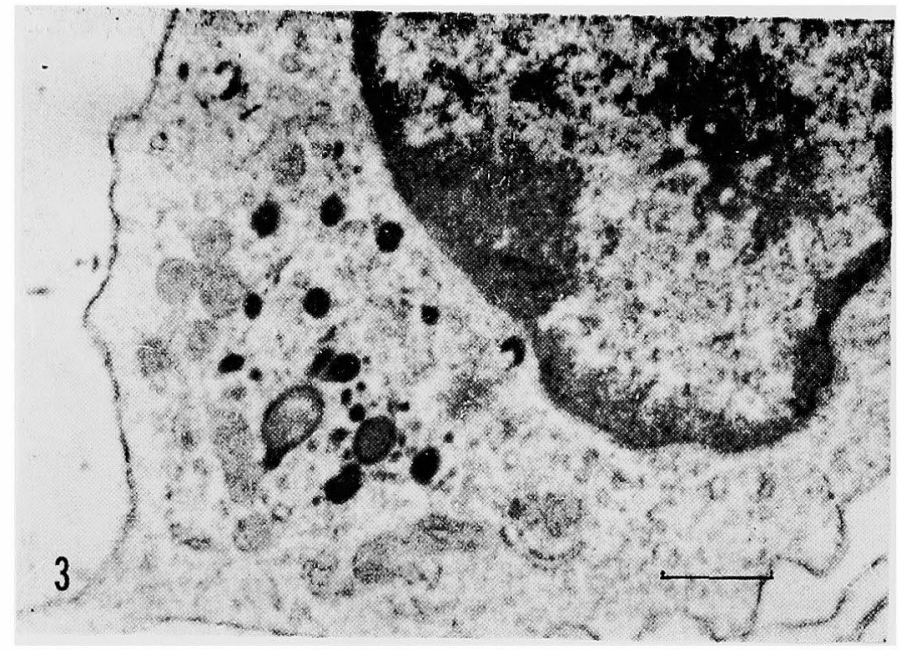

Fig. 3. Free round histiocyte, 4 days after local injection of typhoid vaccine. A number of Golgi granules are seen. One of them is just going to rupture.

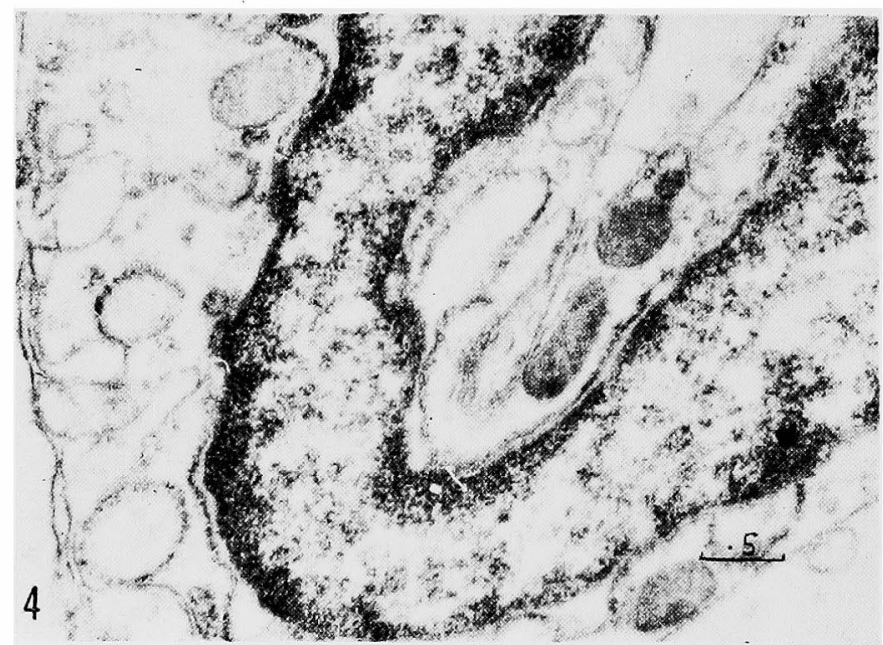

Fig. 4. Fibrocyte, without local treatment. Several ovoid granules are seen. Some of them are partially provided with cristae mitochondriales and some are not. 


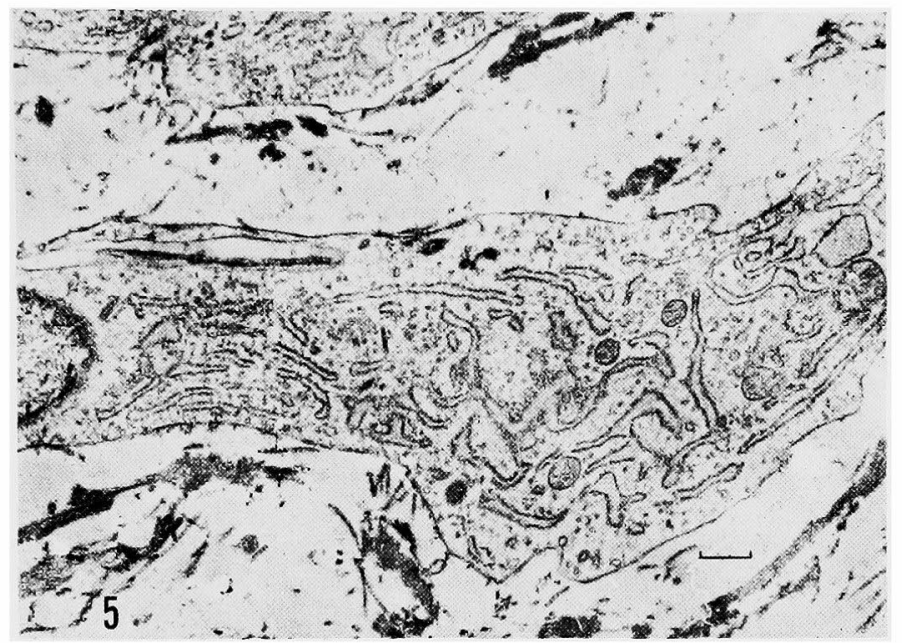

Fig. 5. Fibroblast, 4 days after local injection of typhoid vaccine. Large number of granular endoplasmic reticulum is seen.

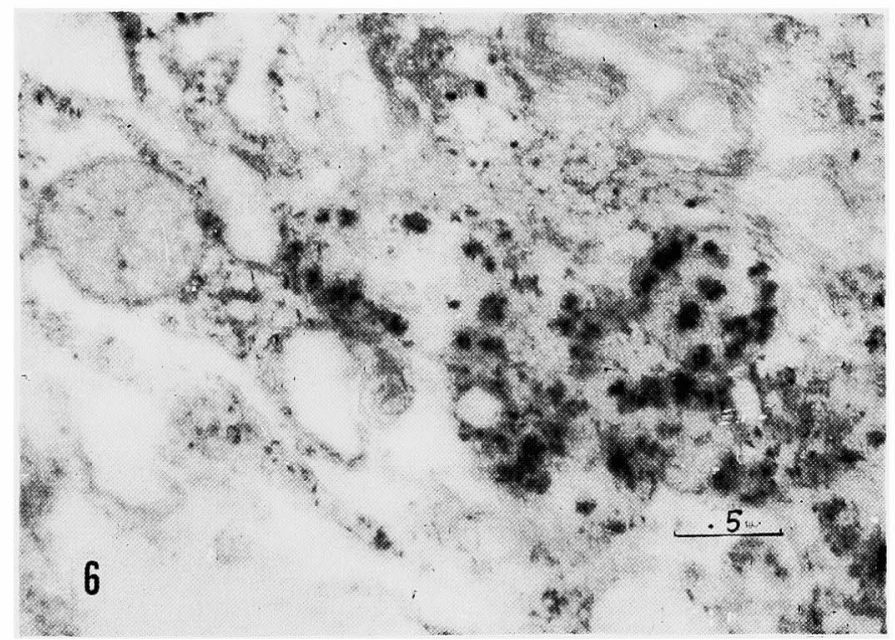

Fig. 6. Fibrocyte, without local treatment. One of the ovoid granule is impregnated with lead deposits. Cristae-like structure is not seen in this granule. 